\title{
Recycling Destroyed Cities: Ruined Archives in Copy
}

\author{
Art
}

Maryam Muliaee

DOI:10.15664/fcj.v19i0.2387

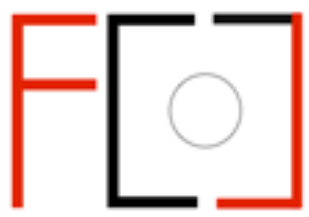

Frames Cinema Journal

ISSN 2053-8812

Issue 19 (March 2022)

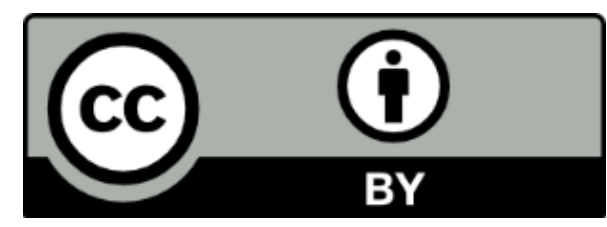


Frames Cinema Journal, Issue 19 (March 2022)

\section{Recycling Destroyed Cities: Ruined Archives in Copy Art}

Maryam Muliaee

Today, the status of the archive is determined by the constant reuse, circulation, and expansion of audio-visual materials. With an unprecedented accessibility of digital tools, artists and filmmakers benefit from this archival instability to make their own collections and create works that consequently disrupt the established meanings of their original sources. Among the tools at hand are copy machines, generative technologies with both reproductive and degenerative capabilities, that have long been of interest to artists. Indeed, the history of copy art is centred around how artists began using copy machines beyond their market-driven purposes. ${ }^{1}$

In this article, drawing from Catherine Russell's articulation of archiveology, I explore the creative potential of the copy machine as a tool to recycle archival materials and practice archiveology. ${ }^{2} \mathrm{I}$ investigate examples that use copiers as tools of archiveology, including my work Recycled Series. Consisting of multiple short animated films, Recycled Series (2016-2019) is a practice-based research project in which I used a black-and-white digital copy machine to recycle a series of original and archival film images in several cycles. In this process, the copier pixilates and warps the text/image, causing the deterioration of original information in an effect known as degeneration. In light of the archiveology, I highlight the aesthetics of degenerated images with a focus on two aspects in these works: first, how the use of the degeneration technique in Recycled Series engenders urban imaginary; second, how archiveology as media art practice reveals the unintended potential of technologies of reproduction such as the copy machine. I conclude that Recycled Series's offering as placed in the context of archiveology is twofold: it does not only 
Frames Cinema Journal, Issue 19 (March 2022)

allow us to rethink destroyed cities, but in using the copy machine as a recycling tool, it also addresses the singularity of the technology producing it.

\section{Recycled Series: Work Description}

To make Recycled Series, I have reworked archival films/images with a copy machine through a technique called degeneration technique. In this technique, images are copied for several runs/cycles until the copies of copies of copies are completely deteriorated, faded and erased. This technique allows the images to be entirely transformed. ${ }^{3}$ The degenerated images lose visual coherence and become difficult to read as they gain unique textures and some abstract patterns. Kate Eichhorn argues that when an image is photocopied in iterations, "it migrates from hot to cool in [Marshall] McLuhan's terms - from a medium that requires only limited participation on the part of the reader to one that requires considerable participation."4 In this sense, the degenerated image becomes sensory and engages the viewer's imagination in an active reading process. The degeneration effects (the degree of warping, distortion, and pixilation of the image/text) can vary with each copy machine, depending on the model. In every case, however, this technique flattens the image by wiping out its representational features. Some unpredictable accidents are inevitable in the process of degeneration, such that each replica becomes notably distinct from its original. Like a palimpsest, the degenerated images bear gradual marks of simultaneous subtractionaddition from the copy machine.

In one of the pieces from this series, titled Recycled Tehran (2016), I degenerated the stills from footage shot by a mobile phone with a copy machine. The original footage shows urban scenes in a gentrified neighbourhood in Tehran. The voice-over narration reveals an account of a middleaged man who revisits the area. While recording with his mobile phone camera, he describes the 
changes he observes in the neighbourhood where he had lived in the past. The observations are combined with the narrator's personal recollections that encourages the audience to (re)imagine the places, images of which are simultaneously being degenerated and erased in my reuse of the materials. To make this piece, I first printed the stills from the mobile phone footage on paper and recycled the copies for 15 runs. I then photographed the degenerated images on an animation stand and re-animated them in a new digital sequence.
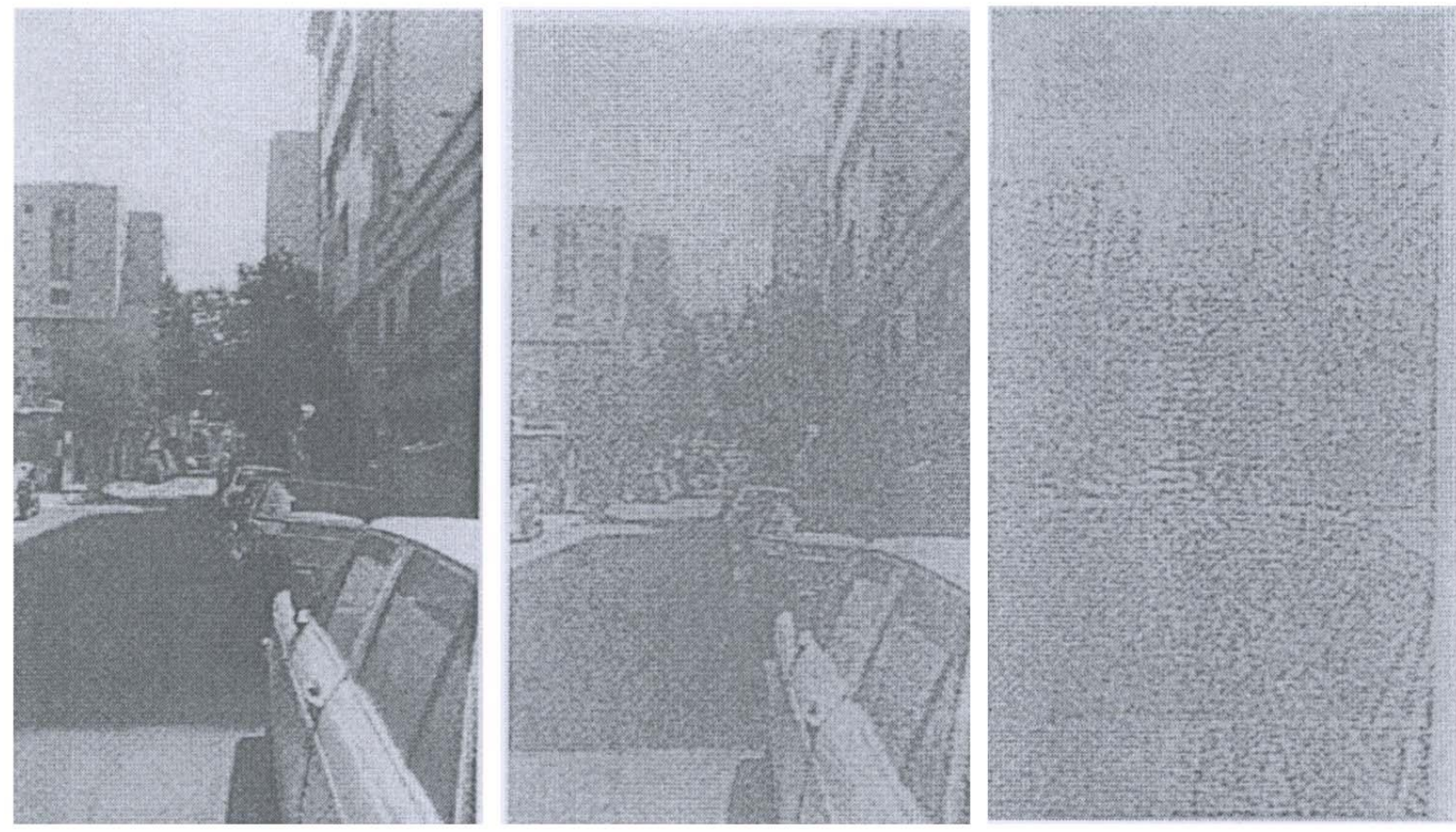

Figure 1: Stills from Recycled Tehran, 2016, Maryam Muliaee, digital video, degeneration effects in cycles 3, 7, and 12, image courtesy of the artist Maryam Muliaee. 

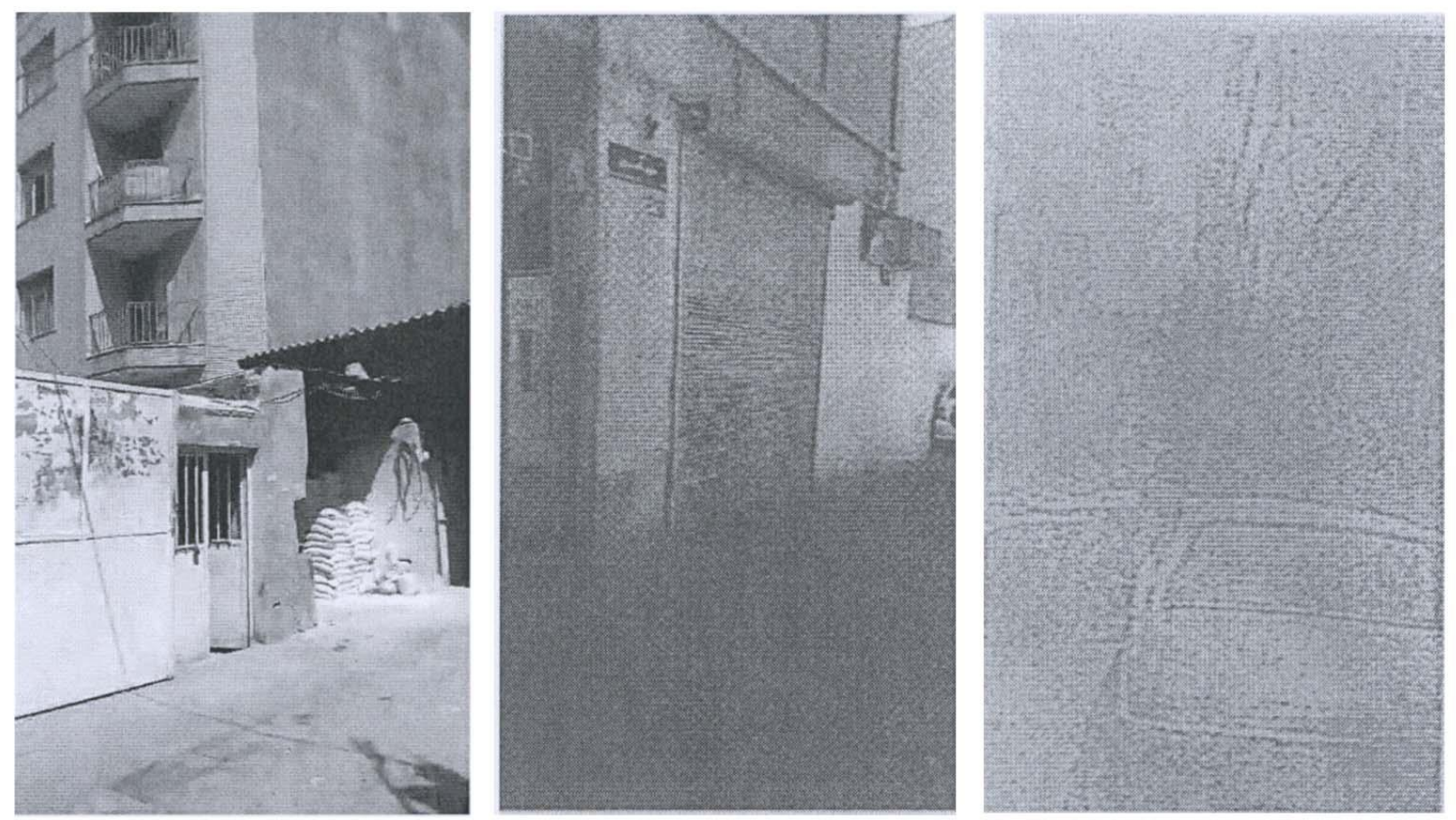

Figure 2. Stills from Recycled Tehran, 2016, Maryam Muliaee, digital video, degeneration effects in cycles 2, 4, and 11, image courtesy of the artist, Maryam Muliaee.

In another piece from this series, titled Survival (2017), I used a copy machine to degenerate stills from a compilation of ten short video clips of historical footage extracted from newsreels, and public archives on the internet. ${ }^{5}$ Each clip shows a ruined location/site around the world that suffered severe damage in war. ${ }^{6}$ I degenerated the stills in 12 cycles and then re-animated them into a new sequence. The soundtrack of the work combines the noises of a copy machine with the voice of journalist Edward R. Murrow, extracted from his narration of a 1951 documentary, in which he explains how American families can protect themselves during a nuclear attack. Watching the recycled video from beginning to the end, viewers become witnesses to the degeneration effects intensified in time - the cycles the copy machine takes to completely ruin the images. 
Frames Cinema Journal, Issue 19 (March 2022)

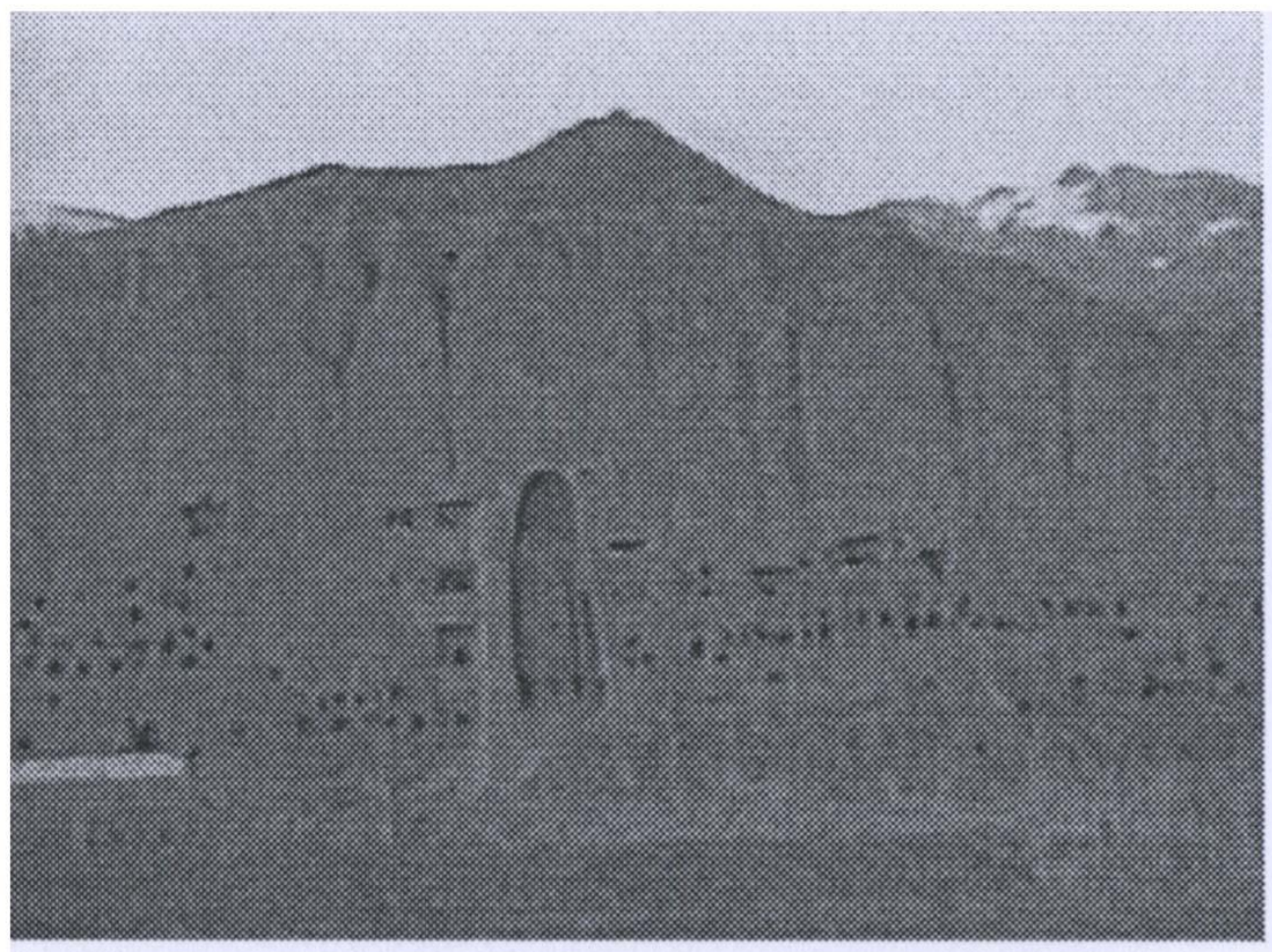

Figure 3: Still from Survival, 2017, Maryam Muliaee, digital video, degeneration effects in cycle 2, image courtesy of the artist Maryam Muliaee.

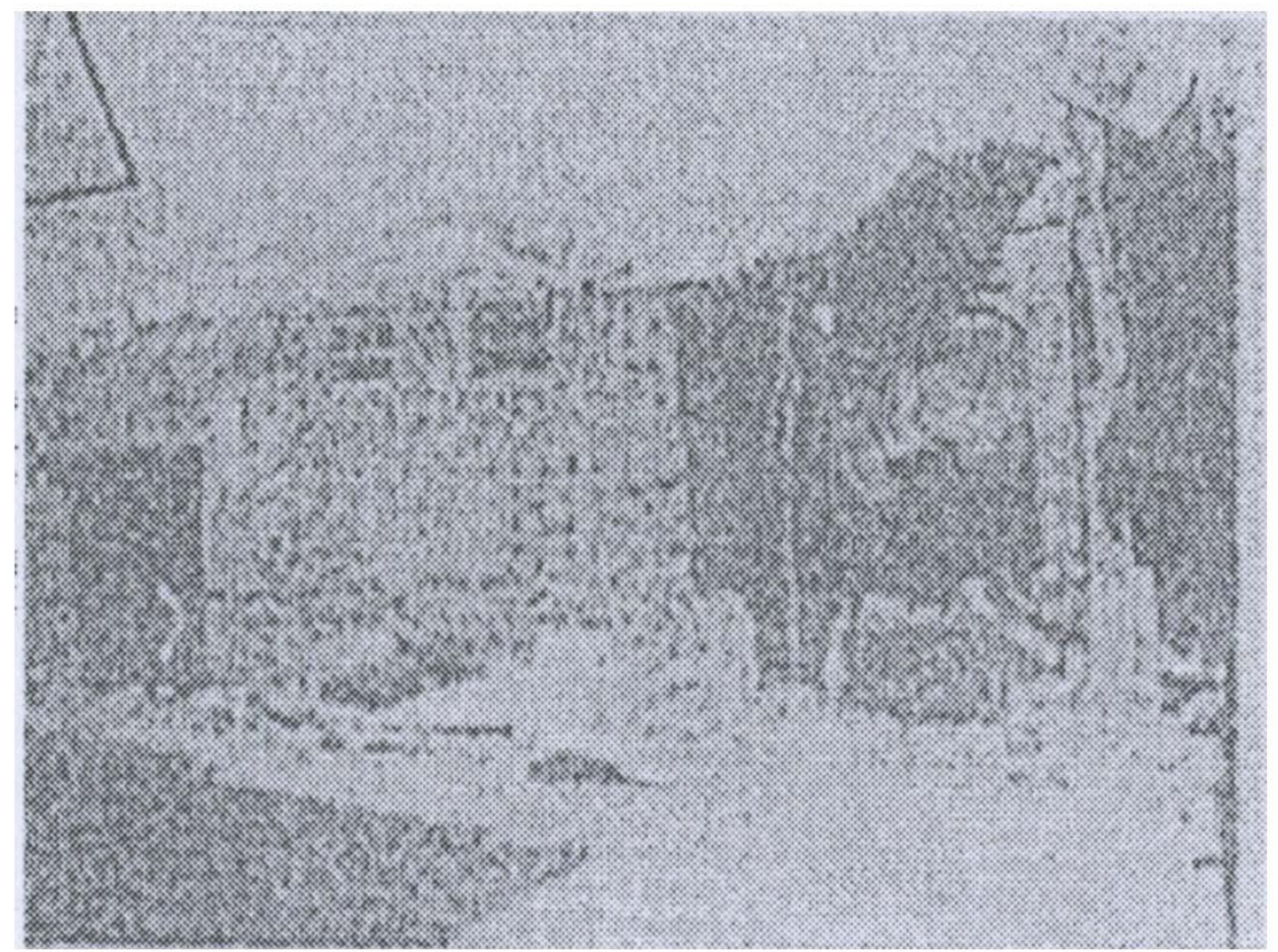

Figure 4: Still from Survival (2017), Maryam Muliaee, digital video, degeneration effects in cycle 9, image courtesy of the artist Maryam Muliaee. 


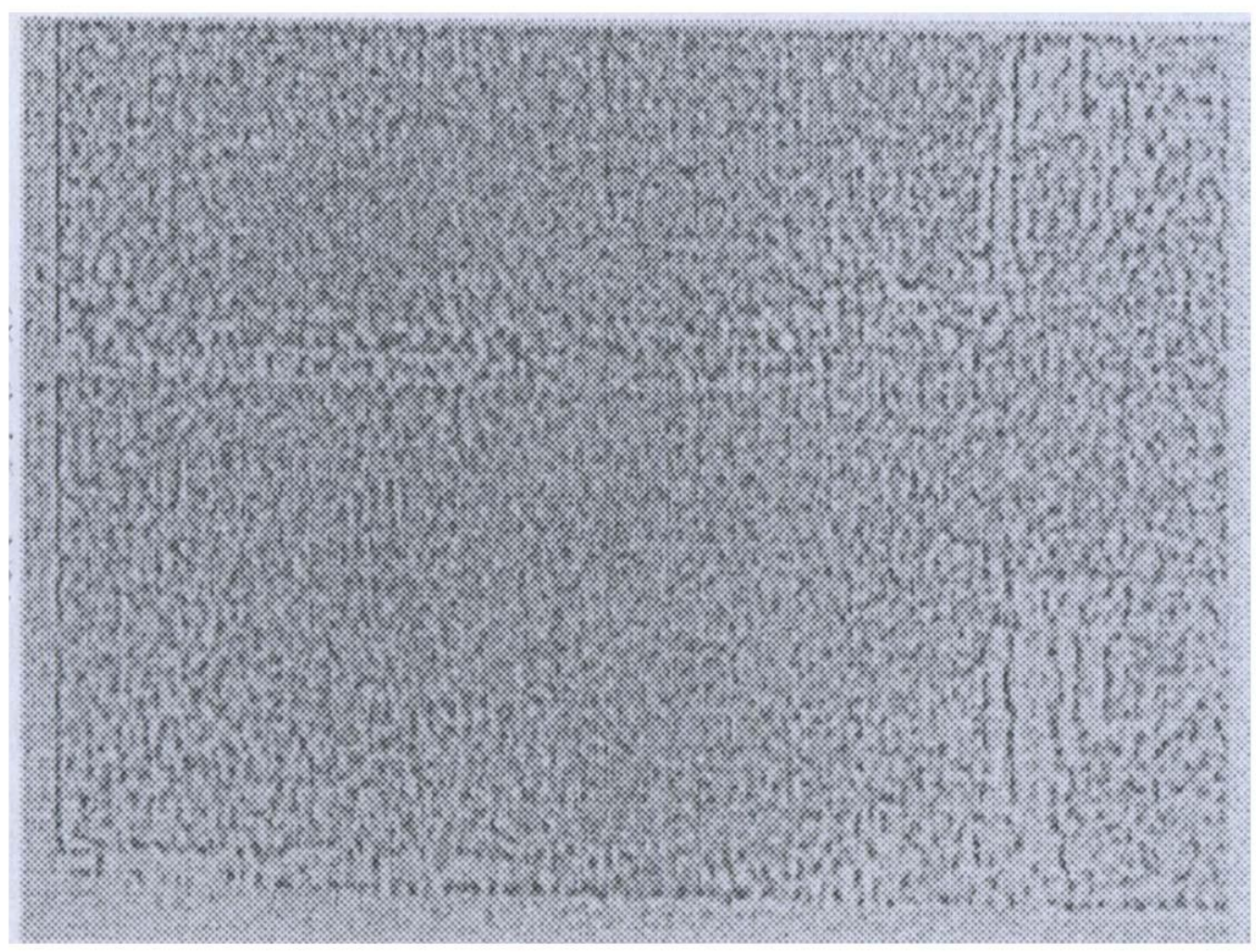

Figure 5. Still from Survival (2017), Maryam Muliaee, digital video, degeneration effects in cycle 12, image courtesy of the artist Maryam Muliaee.

The degenerated images in Recycled Series play a game of doubles with the subject of ruins. On the one hand, we see the images of actual places/sites that have been destroyed (either through urban development or war); on the other hand, we encounter the artificial ruins that the copier generates. These virtual ruins are flattened images whose representational characters are distorted and erased. In this sense, Recycled Series is made with the ruined archives of archival ruins.

\section{Practicing Archiveology with a Copy Machine}

Russell defines archiveology as "a media art practice," referring to "the reuse, recycling, appropriation, and borrowing of archival material that emerge "in many formats, styles, and modes." ${ }^{77}$ She explores a variety of archival materials that can be used in films, pointing to the power of archiveology to speak through the archive, create new messages, and change our view of the past. With this in mind, archiveology remains open to a multiplicity of approaches, techniques, 
and tools with which the archival materials can be recycled. Recycled Series examines the use of an unusual tool such as a copy machine to rework film images. It deteriorates images to create new meanings with their ruins. Reusing the ruined archive (that the copy machine can generate) in the film, it does not only demonstrate the potential of archiveology to rethink destroyed cities in Recycled Series, but it also addresses the technology producing it. In the following paragraphs, building on two characteristics in archiveology, namely, its frequent engagement with the theme of city and its potential as a media art practice to study and reveal the tools of recycling, I outline what Recycled Series has to offer.

A frequent theme that archiveology takes up is the theme of the city. It reworks the city films archival materials with urban scenes and the images of places around the world. Rendering cities in different versions, archiveology extends the meanings and experiences of the cities: "like the archive, [city] is a living, breathing entity as 'documents' are continually added, and more importantly, continually "re-discovered." cinema, the practice of archiveology becomes a generative force of urban imaginary. The term urban imaginary refers to "the ways cities are rendered in different media." in Giuliana Bruno's words. ${ }^{9}$ The city, as she argues, "is inseparable from its own image, for cities practically live in images." ${ }^{10}$ Copy machines, with their distinct archival output (in the forms of gritty images and ruined archives), are bound to have implications for collective urban imaginations as well. ${ }^{11}$ The ruined films/images that the copy machines generate are experienced in both material and subjective conditions, and let us imagine cities in their variations, potentialities, and projections.

Likewise, assembled through ruined images, Recycled Series presents us with an imaginary extension of the actual ruined cities. Stripped of their representational characters due to 
degeneration effects, the degenerated images in Recycled Series no longer offer their audience an easy reading. Unlike their original source materials, the ruined images fail at the task of representation and become the antithesis of city films: they echo with absence, but their evocative absence paradoxically encourages their viewers to fill in the lacunae with new meanings and imaginations. In these works, the degenerated images form a (media-generated) subversive landscape out of the cities whose images are borrowed, reused, and eventually degenerated. Within this transformation, the ruined images become new territories to reclaim and other homes to return to.

Like a phoenix rising from the ashes, new places, territories, experiences, and identifications are built into the poor images. German media artist, Hito Steyerl, refers to the poor image as "a copy in motion," that is compressed and lost quality to gain speed in the networks of mass digital distribution channels. ${ }^{12}$ The poor image is recognised with the marks of its displacements, and its value is redefined: as "a ghost of an image," it sets an example of "imperfect cinema."13 The degenerated images in Recycled Series are also poor images. The rematerialisation process - as the stills are converted from the digital version into prints and from the prints back into the digital format in several runs in these works - deteriorates the quality of these images and opens us to the realm of material images. The degeneration effects break the spatial depth in the images and turn the viewers' attention to their surface and textures. ${ }^{14}$ The gritty textures that destroys the image, simultaneously adds to its ruin, setting up an intriguing connection between the content and form. In this way, the recycling process reveals the excess of its medium: what copy machines can do beyond serviceability. The ruined images of Recycled Series speak of the technology that generated them. In this capacity, Recycled Series propounds an important aspect of archiveology, that is, the potential of archiveology as a media art practice. The task of media art is considered to 
"make and keep us sensible" to what usually remains concealed within the archive and its technologies. ${ }^{15}$ This establishes archiveology with the power to reveal the unintended potential of technologies of reproduction such as the copy machine. Recycled Series verifies this promise in archiveology by producing and reusing the ruined images in new narratives with a copy machine.

To recognise archiveology as such means to acknowledge that recycling the archival materials into new works is equally important as exploring the technologies of archives in practice of archiveology. The digital era, with ceaseless technical changes, requires artists and filmmakers to investigate new and old formats in which archives are constantly renewed and remade when working with archival materials. In this role, with the possibility of "speaking back to the technologies of production at the same time as they speak back to the image archive," archiveology connects itself to media archaeology. ${ }^{16}$ Therefore, the practitioners of archiveology become like inventors who are "frequently transforming film into new media by using digital techniques, thereby challenging norms of authenticity, media specificity and origins that have traditionally been attached to the archive."17

Russell also emphasises the implication of Derrida's "archive fever" for archiveology: how, in archives, we always deal with the ruination of archival materials, such that "archival film practices work against the archive itself by fragmenting, destroying, and ruining the narrativity of the source material." 18 What follows is an emphasis on the formation of "anarchives" in practices of archiveology. The term "anarchives," according to Siegfried Zielinski, is "a complementary opposite and hence an effective alternative to [the official] archive."19 With an interest in multiplicity and variations, archiveology overlaps Zielinski's definition of media art and his model of AnAnarchaeology: "an ongoing process [that] reshapes and reinterprets the materials from 
which memories are made." 20 Therefore, the production or revelation of "anarchives" becomes a key part of archiveology practices. The ruined images in Recycled Series are anarchives, reused and reassembled rather than discarded, to shape new stories. In this sense, I consider archiveology an intervention in media archaeology: a mode and means of storytelling within media archaeology that allows "the attending to the technologies of media production and exhibition" to be entangled with (archaeological) film practices. ${ }^{21}$ In this mode, the archiveologist can be compared to a "craftperson" whose work resembles a "ruin that stands on the site of an old story."22 Recycled Series bears this out further by ruining the film images with a copy machine, as Russell describes, to "awaken us to new meanings and new histories that can be produced from the ruins of the past." ${ }^{23}$ The footage of cities in Recycled Series is destroyed to build, redeem and reimagine something new. As an archaeological tool, the copy machine, when used in a nonstandard way and against its original task, reveals its unseen quality: the capacity to degenerate, to ruin, and to create.

\section{Copy Machines and their Ruined Archives}

Recycled Series comes with notable predecessors. Soon after their arrival on the market, the unintended potential of copy machines began to be explored by artists who used them as imaging tools rather than reproduction machines. Many of the early artistic works with copy machines challenged the limits of these reproduction technologies and also succeeded in playing with the materiality of the archives being engaged in these creative practices. In 1967, German artist Timm Ulrichs used the degeneration technique to recycle the cover of Walter Benjamin's book in 100 runs and challenge the relationship between original and copy. The discourse of "original and copy" is one of the key points in Benjamin's essay "The Work of Art in the Age of Its Technological Reproducibility," where he argued that "reproductive" media such as film and photography lack "aura" - the authenticity or originality in things - possessed by traditional arts 
such as painting and sculpture. ${ }^{24}$ While Benjamin's definition of aura is complex and open to debate, some readings suggest that aura can be reproduced in rematerialisation (of reproducible media such as digital images). ${ }^{25}$ Installed on the gallery's wall as a mural of 100 copies on lettersize papers (A4), the work allowed the audience to see the degrees of the ruination of a single image in 100 cycles. In reference to Benjamin's own work, Ulrichs' work suggested that the machine can ultimately change the meaning of a text and reverse the loss of aura.

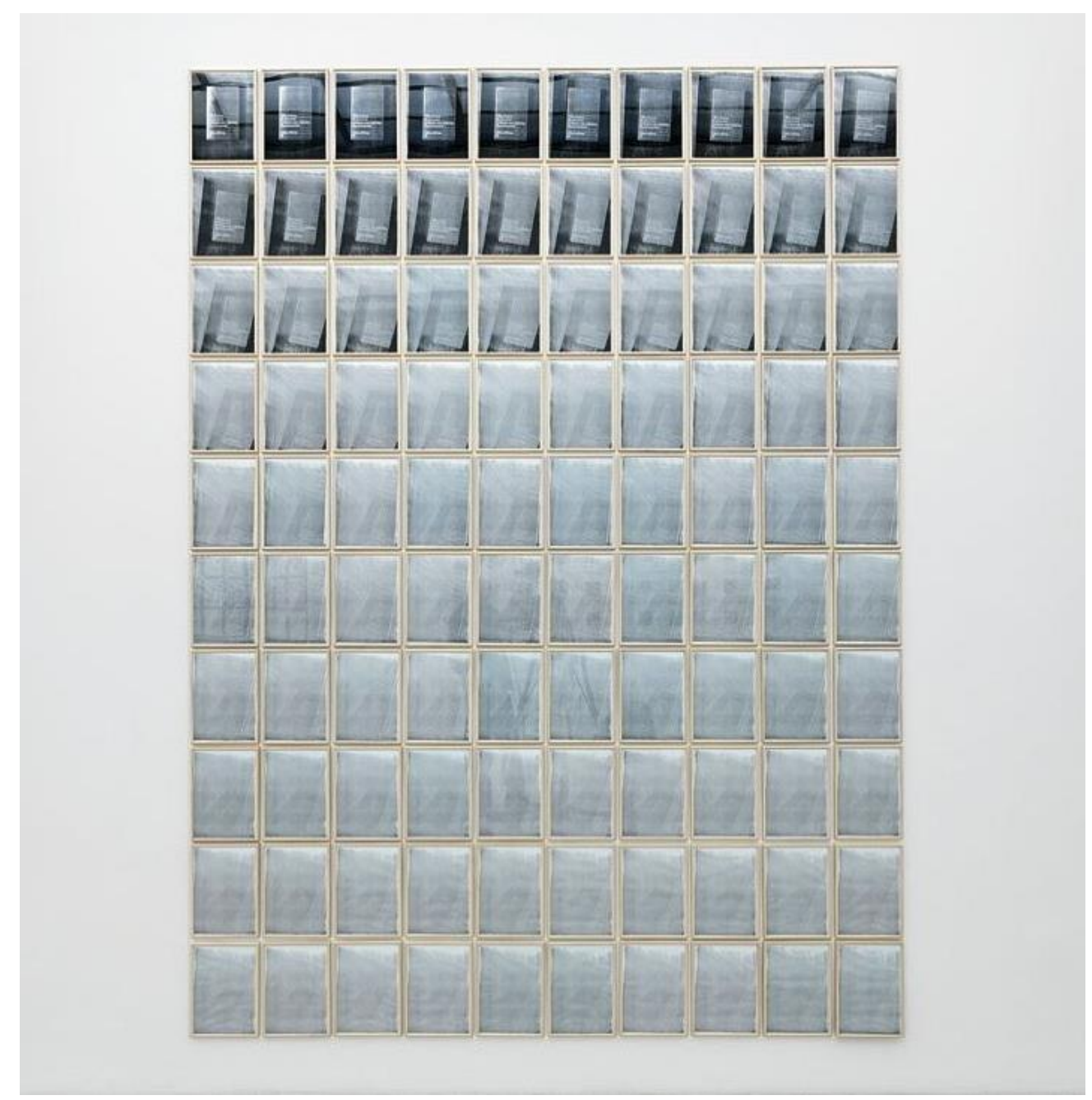

Figure 6: Die Photokopie der Photokopie der Photokopie der Photokopie, 1967, Timm Ulrichs. Sequence of 100 black-and-white photocopies, wooden frames, 11.7 x 8.26 inches each. Image courtesy of the artist Timm Ulrichs and Wentrup Gallery. 
Likewise, Australian artist Ian Burn degenerated a series of images with a copier in a work titled Systematically Altered Photographs (1968) to make a political commentary on the Australia's history of colonialism. Selected from commercial magazines dedicated to promoting Australian tourism, the original images depicted different places of the colonised landscape in Australia. However, with the degeneration effects, the copies were illegible and lacked any distinction to attract tourists. Calling attention to the displacement and absence of native people from their land, the degenerated images in Burn's work deformed the Westernised representation of the Australian landscape.

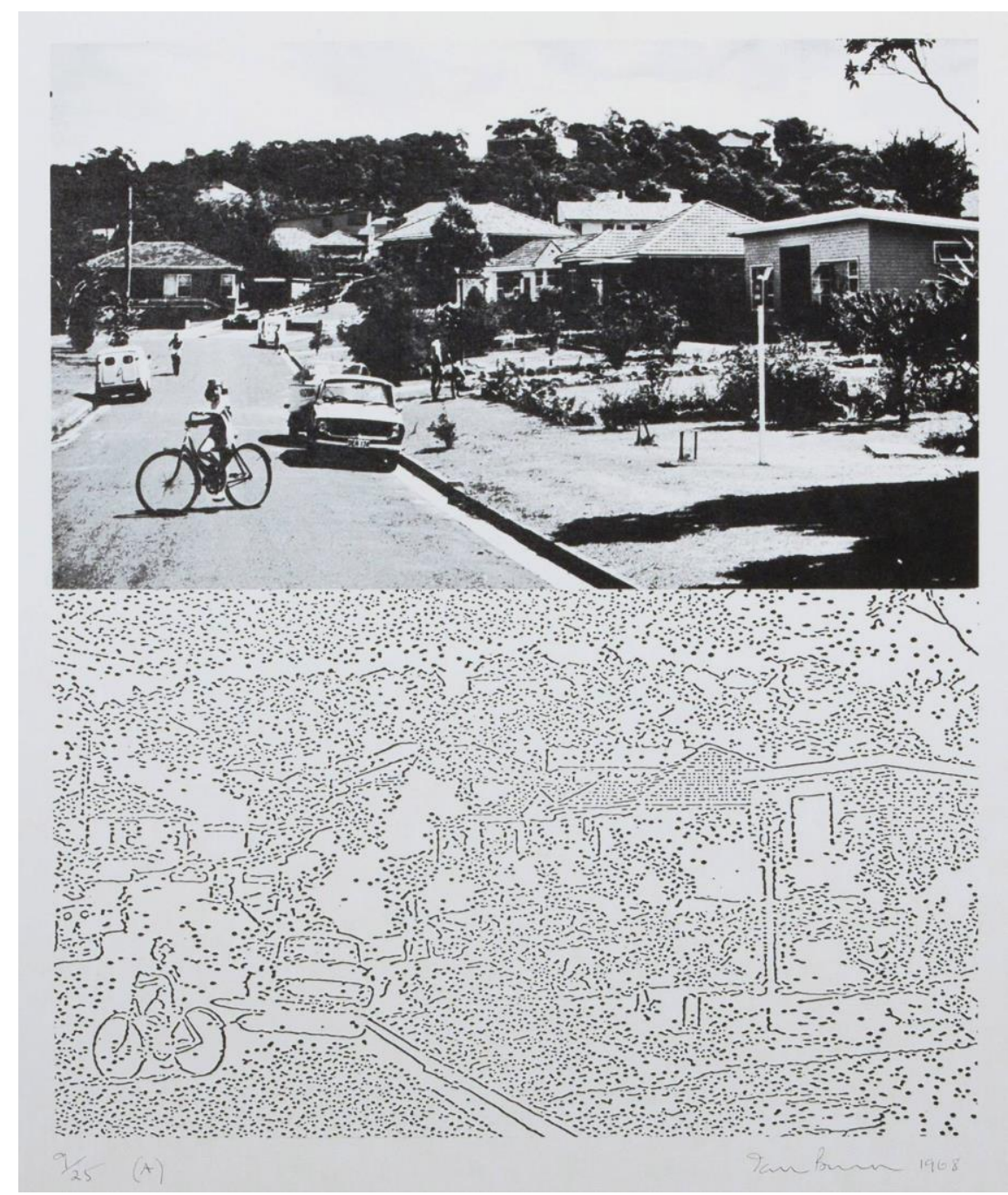

Figure 7. Systematically Altered Photographs, 1968, Ian Burn, print, Museum of Contemporary Art, gift of Terry Smith, 1997, image courtesy the artist and Museum of Contemporary Art Australia, the Estate of Ian Burn. Photograph: Jessica Maurer. 
Another practice of archiveology with copy machine is Vexations (2016-17) by Canadian poet Derek Beaulieu who degenerated a one-page score of French composer Erik Satie using ten different copy machines. In the original composition, Satie advises the players: "In order to play the theme 840 times in succession, it would be advisable to prepare oneself beforehand, and in the deepest silence, by serious immobilities. ${ }^{26}$ For Beaulieu, degeneration took the length of 10 volumes (a total of 840 variations) until the final image was completely ruined or "decomposed," in Beaulieu's own words. ${ }^{27}$ By generating an archive of ruined images, the copy machine let the artist multiply Satie's score into new meanings and interpretations. The illegibility of degenerated images embodies the composer's interest in silence as a form of miscommunication.
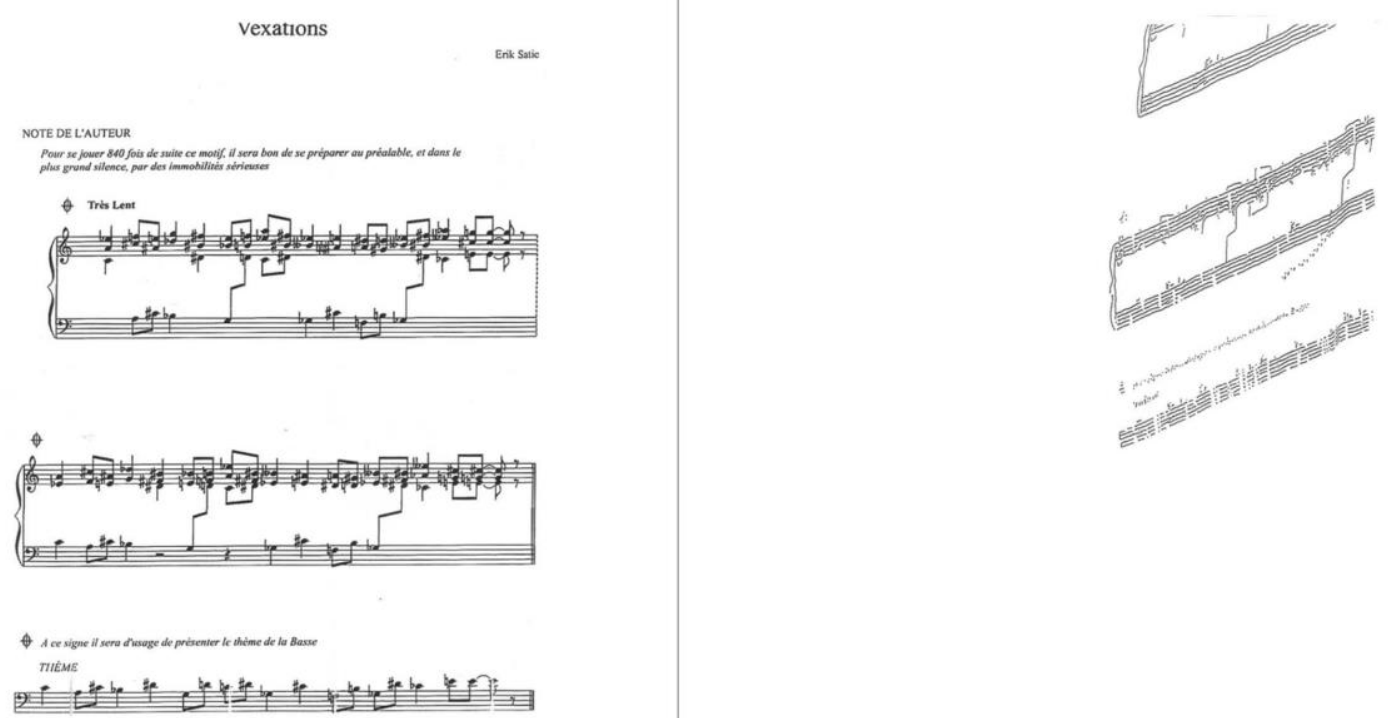

Figure 8: VEXATIONS Book 1: Lexmark XM9155, 2016, Derek Beaulieu, print, the first and last pages of the book, image courtesy of the artist, Derek Beaulieu. 
These artists' (mis)treatment of the copy machine belies an understanding of technology that is usually ignored or obscured in the name of technology's putative infallibility. Their works capture a moment in which technology's perfection becomes almost impossible. The degenerated images in these works shift our attention to the nonhuman agency: the other side of tools and their failures. This is the condition in which archiveology "involves the interface of human and machine," as Russell argues, and brings artists and media technologies together as active agents of artistic creation. ${ }^{28}$ Rather than necessarily working against the archive, the ruined archives in copy art, extend the imaginations of the archive and offer openings to new interpretations and knowing of the past.

Despite today's hegemony of digital technologies that play a heavy role in the discourses of digital arts, copy machines still remain unique potential tools in artistic works, especially in the practice of archiveology. Using a copy machine to recycle film images can bring the aesthetics of ruined archives into film and media art. In this trajectory, archiveology couples the practices of storytelling with the study and (re)discovery of the technologies of recycling. As artists/filmmakers become archiveologists, their works reveal the agency of tools that often remain concealed from our perception and attention. In this capacity, archiveology challenges the norms of authenticity and media specificity and becomes a condition of artistic co-creation with technology. The discussed works in this article support this thesis and how archiveology enables a sensory mode of experience of the archive, destructed and reconstructed in the forms of ruined archives through the use of copy machines and degeneration techniques. 


\section{Notes}

${ }^{1}$ Sonia Landy Sheridan, "Generative Systems versus Copy Art: A Clarification of Terms and Ideas." Leonardo 16, no. 2 (1983): 103-108.

${ }^{2}$ Catherine Russell, Archiveology: Walter Benjamin and Archival Film Practices (Durham, NC: Duke University Press, 2018).

${ }^{3}$ This visual effect, known as degeneration, is a distinctive feature of copy machines, widely favored by artists since the early period of xerox/copy art in the 1970s. See Patrick Firpo, et al. Copy Art: The First Complete Guide to the Copy Machine (Horseguard Lane Productions, 1978).

${ }^{4}$ Kate Eichhorn, Adjusted Margin: Xerography, Art, and Activism in the Late Twentieth Century (Cambridge, MA: MIT Press, 2016), 42.

${ }^{5}$ The videos were extracted from the websites of British Pathé, BBC, ABC, NBC, Euronews, and YouTube.

${ }^{6}$ The archival videos include aerial and ground shots in black and white of atomic bomb destruction in Hiroshima and Nagasaki during World War II in Japan; footage of IS damage to historical sites in Syria in Aleppo and Palmyra, and in Iraqi ancient city of Nimrud; footage of Taliban destruction of the world largest standing Buddhas in Afghanistan's Bamiyan.

${ }^{7}$ Russell, Archiveology, 1.

${ }^{8}$ Catherine Russell, "Archiveology," Research in Film and History 1 (2018): 14.

${ }^{9}$ Giuliana Bruno, "Construction Sites: Fabricating the Architectural Imaginary in Art," in Automatic Cities: The Architectural Imaginary in Contemporary Art (La Jolla, CA: Museum of Contemporary Art San Diego, 2009), 38.

${ }^{10}$ Ibid, 38.

${ }^{11}$ Eichhorn, Adjusted Margin, 24.

${ }^{12}$ Hito Steyerl, "In Defense of the Poor Image." e-flux, no. 10, 2009, accessed 20 Nov 2021, https://www.e-flux.com/journal/10/61362/in-defense-of-the-poor-image/.

${ }^{13}$ Ibid.

${ }^{14}$ For a more detailed discussion on the materiality of ruined images, see Maryam Muliaee, "Media-asthings: The Intensified Materiality of Degenerated Images." Metacritic 7, no. 1 (2021): 40-57.

${ }^{15}$ Siegfried Zielinski, "Thinking About Art after the Media: Research as Practised Culture of Experiment," in The Routledge Companion to Research in the Arts (London and New York: Routledge, 2011).

${ }^{16}$ Russell, Archiveology, 17.

${ }^{17}$ Ibid, 12.

${ }^{18}$ Ibid, 12.

${ }^{19}$ Siegfried Zielinski and Geoffrey Winthrop-Young, “AnArcheology for AnArchives: Why Do We Need - Especially for the Arts - A Complementary Concept to the Archive?" Journal of Contemporary Archaeology 2, no. 1 (2015): 121.

${ }^{20}$ Ibid, 122.

${ }^{21}$ Russell, Archiveology, 15.

${ }^{22}$ Benjamin cited in Russell, Archiveology, 22.

${ }^{23}$ Russell, Archiveology, 14.

${ }^{24}$ Walter Benjamin, "The Work of Art in the Age of Mechanical Reproduction," in Selected Writing, Vol. 2, 1913-1926 (Cambridge, MA: Harvard University Press, 1996).

${ }^{25}$ See Boris Groys, "The Aura of Profane Enlightenment," in The World (Maybe) Fantastic (Exhibition Catalogue, Sidney Biennale, 2002): 1-2.

${ }^{26}$ Satie cited in Derek Beaulieu, Vexations 2: Xerox Workcentre 5755 (Ontario: Puddles of Sky Press, 2016). 
${ }^{27}$ Ibid.

${ }^{28}$ Russell, Archiveology, 115.

\section{Bibliography}

Beaulieu, Derek. Vexations 2: Xerox Workcentre 5755. Ontario: Puddles of Sky Press, 2016.

Benjamin, Walter. "The Work of Art in the Age of Mechanical Reproduction," in Selected Writing, Vol. 2, 1913-1926, Harvard University Press, 1996.

Bruno, Giuliana. “Construction Sites: Fabricating the Architectural Imaginary in Art.” In Automatic Cities: The Architectural Imaginary in Contemporary Art, 37-55. La Jolla, CA: Museum of Contemporary Art San Diego, 2009.

Eichhorn, Kate. Adjusted Margin: Xerography, Art, and Activism in the Late Twentieth Century. Cambridge, MA: MIT Press, 2016.

Firpo, Patrick. et al. Copy Art: The First Complete Guide to the Copy Machine. Horseguard Lane Productions, 1978.

Groys, Boris. “The Aura of Profane Enlightenment.” In The World (Maybe) Fantastic. Exhibition Catalogue. Sydney: Sidney Biennale, 2002.

Muliaee, Maryam. "Media-as-things: The Intensified Materiality of Degenerated Images." Metacritic 7, no. 1 (2021): 40-57.

Russell, Catherine. Archiveology: Walter Benjamin and Archival Film Practices. Durham, NC: Duke University Press, 2018.

Russell, Catherine. “Archiveology: Walter Benjamin and Archival Film Practices.” Research in Film and History. Special Issue: The Long Path to Audio-visual History 1 (2018): 1-22. 
Frames Cinema Journal, Issue 19 (March 2022)

Sheridan, Sonia Landy. "Generative Systems versus copy art: A clarification of terms and ideas." Leonardo 16, no. 2 (1983): 103-108.

Steyerl, Hito. "In Defense of the Poor Image." e-flux journal 10, no. 11 (Nov 2009), accessed 30 Oct 2020, https://www.e-flux.com/journal/10/61362/in-defense-of-the-poor-image/

Zielinski, Siegfried. “Thinking About Art After the Media: Research as Practised Culture of Experiment." In The Routledge Companion to Research in the Arts (London and New York: Routledge, 2011): 293-312.

Zielinski, Siegfried, and Geoffrey Winthrop-Young. "AnArcheology for AnArchives: Why Do We Need - Especially for the Arts - A Complementary Concept to the Archive?" Journal of Contemporary Archaeology 2, no. 1 (2015): 116-125.

\section{Author Biography}

Maryam Muliaee $(\mathrm{PhD})$ is a media artist-scholar, currently a Post-doctoral Associate in the Department of Critical Media Practices and Intermedia Art, Writing and Performance in University of Colorado Boulder. She is the co-founding editor of MAST (the peer-reviewed journal of Media Art Study and Theory, published by the University at Buffalo) and has published her research in peer-reviewed journals and book collections in the contexts of media archaeology and noncommunication aesthetics in media art. 